\title{
Small bowel function after aortic surgery
}

\author{
S.G.E. Barker, R.D.A. Dodds, A. Middlemiss, C.E. Bennett, M.H. Russell, \\ B.C. Sellick and M.H. Thomas
}

Departments of Surgery and Anaesthetics, St. Peter's Hospital, Chertsey, Surrey KT16 0PZ, UK

\begin{abstract}
Summary: One cause of post-operative morbidity in the elective repair of abdominal aortic aneurysms is the development of a paralytic or 'adynamic' ileus. In a series of 20 consecutive patients undergoing such a procedure, the maintenance of small bowel motility and absorptive capacity in the immediate post-operative period was assessed using barium sulphate and xylose passed down a naso-duodenal tube sited at the time of surgery. This simple study demonstrated that small bowel function was preserved in all cases, and hence that patients could be fed enterally via naso-duodenal tube (in particular using very low residue formulae) rather than using costly parenteral regimens, should an ileus persist.
\end{abstract}

\section{Introduction}

Elective repair of abdominal aortic aneurysms in a vascular centre now carries a mortality of less than $5 \%,{ }^{1}$ although this can be increased to $40 \%$ if emergency cases are included. ${ }^{2}$ Causes of major post-operative morbidity include chest infection, cardiac arrhythmias, congestive cardiac failure, myocardial infarction, renal failure and, in approximately $1-2 \%$, the development of a paralytic or 'adynamic' ileus, as with any operation that involves dissection of the retroperitoneum. ${ }^{3}$ Traditional management of paralytic ileus includes restriction of oral fluids, naso-gastric aspiration and intravenous fluid replacement. If the paralytic ileus persists, then parenteral feeding may be required to maintain adequate nutrition.

In a series of 20 patients undergoing elective aneurysm repair, we aimed to show by simple means that small bowel motility and absorptive capacity were maintained throughout the postoperative period and hence, that patients could be fed immediately by means of a naso-duodenal tube passed at the time of surgery. In this way expensive parenteral feeding could be avoided.

\section{Patients and methods}

Twenty patients undergoing elective aortic surgery over a 12-month period were included in the study.

Correspondence: S.G.E. Barker, B.Sc., F.R.C.S., c/o The Rayne Institute, 123, Coldharbour Lane, Camberwell, London SE5 9NU, UK

Accepted: 12 February 1991
All operations were performed through a midline incision by the same surgical team. The bowels were packed away behind a large gauze swab and held in place by a self-retaining ring retractor. At operation a long naso-duodenal (ND) tube was passed and carefully placed in the third part of the duodenum. The morning after surgery $25 \mathrm{ml}$ of barium sulphate was injected down the tube followed (in 8 cases) by $5 \mathrm{~g}$ of xylose dissolved in $10 \mathrm{ml}$ water. A plain abdominal X-ray was taken immediately with the patient positioned at $45^{\circ}$ (average 16 hours after surgery) and another, 6 hours later. Films were examined by the same consultant radiologist. The maximum small bowel diameter was measured and the presence of gas/fluid levels noted. The progress of dye down the intestine was also assessed. Multiple blood samples were taken for estimation of xylose absorption over the first hour ( 9 samples/h). Urine samples were taken hourly for 6 hours and then at 24 hours. Xylose levels in blood and urine were measured using the method of Roe and Rice. ${ }^{4}$ Clinical assessments of bowel sounds over a 2-minute period were made after 16 and 22 hours respectively, at the time of the $\mathrm{X}$-rays.

\section{Results}

Review of the barium studies showed a normal small bowel pattern in all 20 cases. No loop of bowel exceeded $2.5 \mathrm{~cm}$ in diameter and no features associated with an ileus or obstruction were seen. Barium had progressed to the jejunum in 8 , ileum in 10 and colon in 2 (Figure 1). Reflux of barium into the stomach occurred in one case probably from 
a
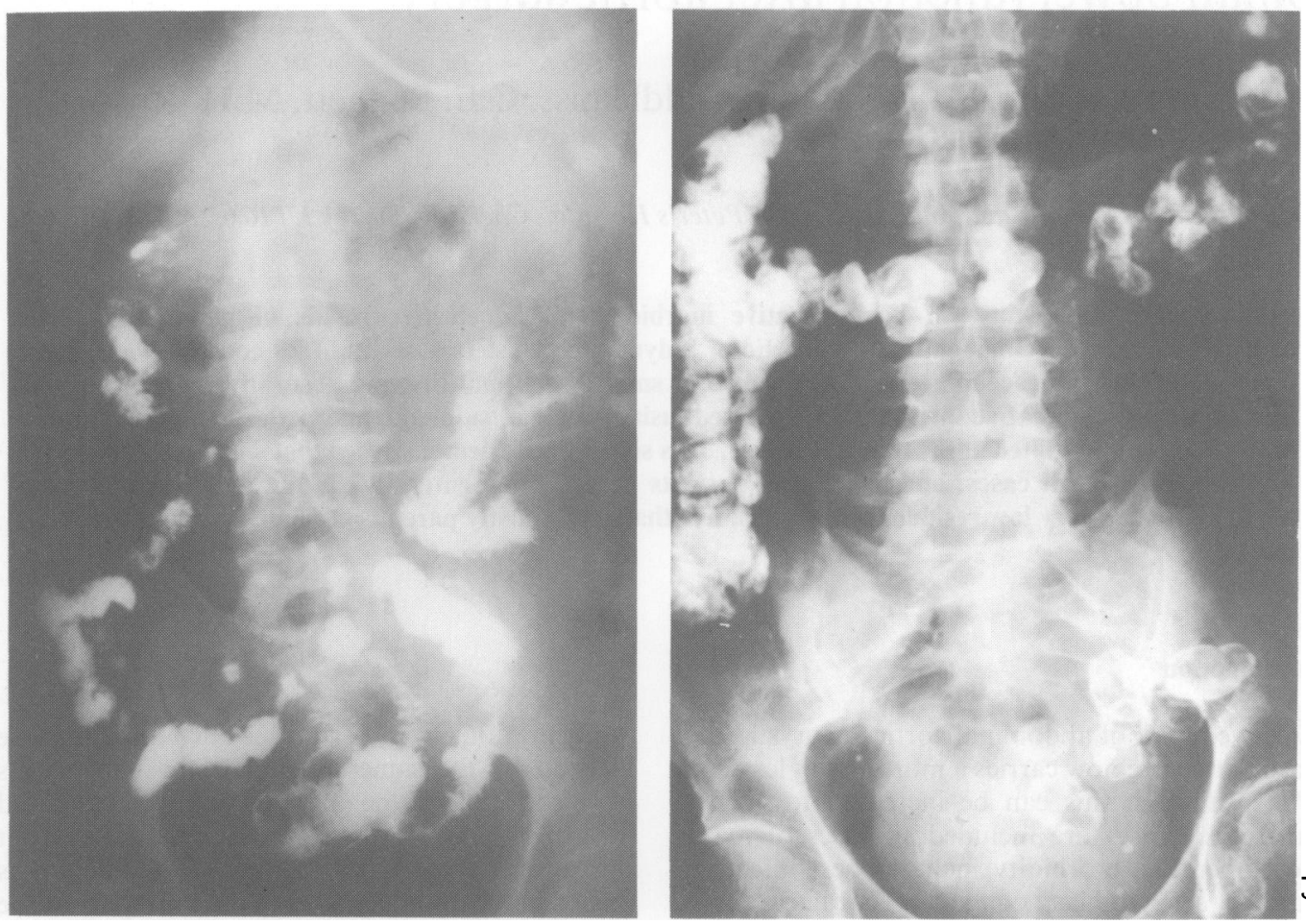

Figure 1 Two patients with barium sulphate in (a) ileum and (b) colon 6 hours after injection into the distal duodenurn via the naso-duodenal tube.

incorrect placement of the tube.

Xylose was detected in the peripheral blood sample 15 minutes after administration into the duodenum in all cases. By 6 hours an average of $24 \%$ (range $16-42 \%$ ) of xylose had been excreted in the urine. These results are similar to those found in normal unoperated people. ${ }^{5}$

In all cases, bowel sounds were not heard within the first $\mathbf{4 8}$ hours after surgery.

\section{Discussion}

It is well recognized that major abdominal surgery, in particular that involving extensive retro-peritoneal dissection, is associated with a period of gastro-intestinal inactivity. ${ }^{6,7}$ Similarly, the differential return of activity along the length of the gastro-intestinal tract is well recorded. ${ }^{7,8}$ Despite this, patients undergoing abdominal aortic aneurysm repair may develop a paralytic or 'adynamic' ileus with absent bowel sounds, which persists and which results in several days of almost absent nutrition before a decision is taken to commence parenteral therapy.
The clinical assessment of return of function is frequently inaccurate especially as bowel sounds require gas/fluid interfaces which are uncommon in normal small bowel. Furthermore, earlier studies have emphasized that it is mainly gastric and colonic function which are reduced post-operatively. ${ }^{9}$

In our small series, a long naso-duodenal (not naso-gastric) tube was easily passed at the time of operation and, importantly, its position confirmed prior to closure. By the simple radiographic means of injecting $25 \mathrm{ml}$ of barium sulphate, we have shown that in all 20 cases the small bowel retained its motility after aortic surgery. There were no gas/fluid levels and no dilated loops seen and, again, in all 20 cases, dye progressed down the alimentary tract.

In normal individuals of 60-80 years of age, $20 \%$ or more of xylose administered orally in solution, is excreted in the urine within 6 hours. $^{5}$ Again, as a simple test of the ability of the gut to absorb at least carbohydrate, we gave our patients $5 \mathrm{~g}$ of xylose dissolved in $10 \mathrm{ml}$ of water the morning after surgery. On average, $24 \%$ of xylose was excreted in the urine within 6 hours. In 
addition, the presence of xylose within the peripheral blood in all cases after 15 minutes would seem to confirm that small bowel absorptive capacity (for carbohydrate) is not hindered.

Enteral feeding regimes (in particular very low residue) can provide adequate post-operative nutritional support in place of the parenteral route. ${ }^{10,11}$ This study would seem to confirm that

\section{References}

1. Crawford, E.S., Saleh, S.A., Babb, J.W. et al. Infra-renal abdominal aortic aneurysm. Factors influencing survival after operations performed for 25 years. Ann Surg 1981, 193: 699-709.

2. Buck, N., Devlin, H.B. \& Lunn, J.N. CEPOD - The report of a confidential inquiry into peri-operative death. The Nuffield Provincial Hospitals Trust, London.

3. Mutirangura, P., Stonebridge, P.A., Clason, A.E. et al. Ten year review of non-ruptured aortic aneurysms. Br J Surg 1989, 76: $1251-1254$.

4. Roe, J.H. \& Rice, E.W. A photometric method for the determination of free pentoses in animal tissues. J Biol Chem 1948, 173: 507-512.

5. Haeney, M.R., Culank, L.S., Montgomery, R.D. \& Sammons, H.G. Evaluation of xylose absorption as measured in blood and urine. Gastroenterology 1978, 75: 393-400. small bowel motility (and probably function) is unaffected in elective repair of abdominal aortic aneurysms. We would suggest that placement of a long naso-duodenal tube at the time of surgery can allow very early post-operative feeding and therefore provide nutrition prior to the possible development of a paralytic ileus and hence a need for costly parenteral regimes.

6. Catchpole, B.N. Smooth muscle and the surgeon. Aust $N Z J$ Surg 1989, 59: 199-208.

7. Sarna, S.K., Bowes, K.L. \& Daniel, E.E. Post-operative gastric electrical control activity (ECA) in man. In: Proceedings 4th International Symposium on Gastrointestinal Motility. Mitchell Press, Vancouver, 1973, pp. 73-83.

8. Baker, L.W. \& Webster, D.R. Post-operative intestinal motility. Br J Surg 1968, 55: 374-378.

9. Wells, C., Rawlinson, K., Tinckler, L. et al. Ileus and post-operative intestinal motility. Lancet 1961, ii: 136-137.

10. Fletcher, J.P. \& Little, J.M. A comparison of parenteral nutrition and early post-operative enteral feeding on the nitrogen balance after major surgery. Surgery 1986, 100: 21-24.

11. Sagar, S., Harland, P. \& Shields, R. Early post-operative feeding with an enteral diet. Br Med J 1979, 1: 293-295. 